\title{
Ecological and epidemiological models should be utilized for reducing covid-19 spread
}

\author{
yoshiyasu takefuji ${ }^{1}$ \\ ${ }^{1}$ Affiliation not available
}

September 16, 2020

Many scientists have discussed what are reasonable or appropriate ecological and epidemiological models of covid-19 $1,2,3$. Their goal lies in that their models can be used for accurately predicting covid-19 spread. Of course, the models are useful, however they should be used in practice for reducing infection risks. The airflow or ventilation control plays a key role in alleviating the infectious diseases spread ${ }^{4}$. The new research was awarded to reduce infection risks for covid-19 ${ }^{5}$. We should use the latest cleanroom strategy for reducing infection risks. Instead of blowing air against human indoor, sucking air against human should be used in ventilation control for disturbing virus transmission to human ${ }^{6}$. A negative pressure room will play a key role in mitigating covid-19 pandemic by controlling the airflow to avoid covid-19 viruses against human bodies ${ }^{6}$.

References:

1. Carlson, C.J., Chipperfield, J.D., Benito, B.M. et al. Don't gamble the COVID-19 response on ecological hypotheses. Nat Ecol Evol 4, 1155 (2020). https://doi.org/10.1038/s41559-020-1279-2

2. Carlson, C. J., Chipperfield, J. D., Benito, B. M., Telford, R. J. \& O'Hara, R. B. Nat. Ecol. Evol. 4 , 770-771 (2020)

3. Araújo, M. B., Mestre, F. \& Naimi, B. Nat. Ecol. Evol .https://doi.org/10.1038/s41559-020-1246$y(2020)$

4. Morawska, L., \& Cao, J. (2020). Airborne transmission of SARS-CoV-2: The world should face the reality. Environment international ,139 , 105730.https://doi.org/10.1016/j.envint.2020.105730

5. RAPID: Smart Ventilation Control May Reduce Infection Risk for COVID-19 in Public Buildings, 2020 https: //www. nsf. gov/awardsearch/showAward? AWD_ID=20296906HistoricalAwards=false

6. Airborne InfectiousDisease ManagementMethods for Temporary Negative Pressure Isolation prepared by Minnesota Department of Health https://www. health. state. mn. us/communities/ep/ surge/infectious/airbornenegative. pdf 